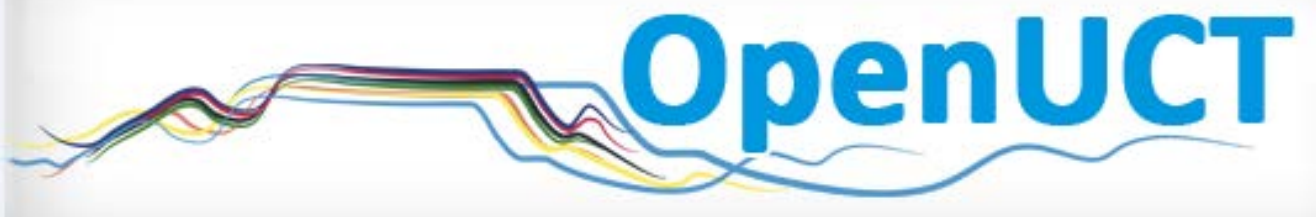

This is the post-print of Jawitz, J. 2009. Academic identities and communities of practice in a professional discipline. Teaching in Higher Education. 14(3): 241-251. DOI: $10.1080 / 13562510902898817$.

It is made available according to the terms of agreement between the author and the journal, and in accordance with UCT's open access policy available:

http://www.openuct.uct.ac.za/sites/default/files/UCTOpenAccessPolicy.pdf, for the purposes of research, teaching and private study. 


\title{
Academic identities and communities of practice in a professional discipline
}

\author{
Jeff Jawitz ${ }^{*}$ \\ Centre for Higher Education Development, University of Cape Town, South Africa
}

\begin{abstract}
This paper explores the dynamics surrounding the formation of academic identities in a context where the nature of academic work is contested both as a result of tensions within the discipline and in response to pressure from both the institution and the field of higher education. It is based on a case study which investigated the process of academic identity formation at the micro level of a department at a South African university. The study revealed a complex relationship between identity construction and participation within the particular configuration of teaching, professional and research communities of practice that defined the academic field in the department. Multiple identity trajectories were evident, indicating the role of individual agency, despite the dominance of a professional community of practice within the department. The arrival of new academics in the department without professional practice experience was found to have created the possibility of a changed notion of the academic within the discipline.
\end{abstract}

Keywords: Academic workplace; identity; communities of practice; discipline; teaching; research; professional

\footnotetext{
*Email: jeff.jawitz@uct.ac.za
} 


\section{Introduction}

This paper analyses data from one case study that formed part of a study of how new academics learn to be effective educators conducted at a research intensive, historically white university in South Africa. The study explored how new academics learnt to judge student performance in complex assessment tasks in three case studies across different disciplines. Two of the case studies have been reported elsewhere (Jawitz 2007; Jawitz 2008 in press). The names of the institution and department have been changed to protect their identities and they will be referred to as the Department of Design at the South African University (SAU).

This paper focuses on an academic department and explores the contested nature of academic identity formation within the Department of Design. It draws on data from interviews with nine of the ten full-time academics, as well as a retired professor who still taught part-time in the department. Interviews with senior academics, Roger, Stuart and Malcolm, provide insight into the changes that had taken place in the department during the previous three decades, including changes in the form of departmental leadership, the relationship between teaching and professional work, the racial composition of the staff and in the shift from modernist to post modernist perspectives in the discipline.

The department offered a three-year undergraduate programme followed by a postgraduate programme. In both programmes the curriculum for each year was structured around a design studio, supported by a set of smaller courses. About thirty part-time teaching staff, mainly professional practitioners, assisted with the design studio and some of the other teaching. Most of the ten full-time academics had been in the department for five years or less. There were four black academic members of staff and two of the academics were female. The term 'black' is used here to refer to persons who would have been previously classified as 'coloured', Indian or African.

\section{Academic identity}

A great deal has been written recently about the changing nature of academic work with several writers commenting specifically on the effect of the new forms of managerialism on academic identities in higher education (Barnett 1999; Henkel 2000; Archer 2008; Clegg 2008).

The conceptualisation of identity used in this study is one that recognizes both individual and broader structural aspects (Henkel 2000; Kogan 2000; Clegg 2008). Academic identity is viewed as both distinctively 'individual and embedded in the communities of primary importance to them' (Henkel 2000, 251). Clegg (2008) argues that identity is a 'multiple and shifting term [which] exists alongside other aspects of how people understand their personhood and ways of being in the world'. It should not be viewed 'as a fixed property, but as part of the lived complexity of a person's project and their ways of being in those sites which are constituted as being part of the academic' (Clegg 2008, 329).

Both the discipline and the institution play an important role in the development of the academic identity (Austin 1990; Clark 1987; Becher and Trowler 2001; Henkel 2000; 
Neumann 2001). The discipline is regarded as the central organizing vehicle within higher education and belonging to a 'disciplinary community involves a sense of identity and personal commitment' (Becher and Trowler 2001, 47). The discipline is the central context within which 'academics construct their identities, their values, the knowledge base of their work, their modes of working and their self esteem' (Henkel 2000, 22). It is the place where 'a sense of academic identity flourishes' (Kogan 2000, 209).

The relationship between teaching and research within the discipline also impacts on the nature of academic work and hence on academic identity (Neumann 2001; Shulman 1993; Clark 1987; Jenkins 2000; Jenkins et al. 2003). In most disciplines teaching is viewed as a generic activity that lies 'on top of' the 'real' academic work, namely research, and is 'unconnected with the disciplinary community at the heart of being an academic' (Neumann 2001, 144). While research usually involves engagement with an academic community, teaching has been characterised as an individual private affair (Clark 1987; Shulman 1993).

\section{Identity construction and participation}

Several authors have drawn on situated learning theory and the concept of communities of practice to analyse the process of academic identity construction (Hodkinson and Hodkinson 2004; Fuller et al. 2005; Trowler and Knight 2000). Situated learning theory argues that knowledge is distributed amongst a community of practice and can only be understood with the 'interpretive support' provided by participation in the community of practice itself (Lave and Wenger 1991, 98). Wenger (1998) regards participation within a community of practice as a 'source of identity' (p. 56). In the process of participation, newcomers' identities change as they are increasingly recognised as belonging to and contributing to a community of practice. The concept of learning as participation therefore helps to explain 'the evolution of practices and the inclusion of newcomers [and] . . . the development and transformation of identities' (Wenger 1998, 13). It has also been argued that activity systems work in tandem with communities of practice and form the place where 'personal identity coalesces, is shaped and re-shaped' (Trowler and Knight 2000, 30).

Identity is built around social engagement and is constantly being renegotiated as individuals move through different forms of participation. However, the process of learning and identity construction is not simply the outcome of participation in the opportunities provided by existing structural arrangements, it is also shaped by the way in which individuals exercise their agency in the workplace (Billett 2004; Fuller, Munro and Rainbird 2004; Knight and Trowler 2000). Each individual's experience will be unique due to 'the inevitable negotiation between the workplace's norms and practices and the individuals' subjectivities and identities' (Billett 2004, 114). As a result a range of trajectories representing differing paths of identity formation emerge linking past and present experiences with future possibilities. Some of the forms that these trajectories can take are described in Table 1.

Learning occurs through participation in activities along the trajectory and contributes to a growing identity within or across communities of practice. Wenger suggests, however, that certain 'paradigmatic trajectories' take on greater significance than 
others as they 'embody the history of the community through the very participation and identities of practitioners.'

Exposure to this field of paradigmatic trajectories is likely to be the most influential factor shaping the learning of newcomers. ... [N] ewcomers are no fools: once they have access to the practice, they soon find out what counts. (Wenger 1998, 156)

But newcomers also have agency that can result in them choosing to engage with an identity trajectory that combines particular forms of participation and non-articipation.

Table 1. Forms of identity trajectories

\begin{tabular}{|c|l|}
\hline Identity trajectory & \multicolumn{1}{c|}{ Description } \\
\hline Inbound & $\begin{array}{l}\text { where newcomers' identities are invested in their future as full } \\
\text { members of a specific community of practice. }\end{array}$ \\
\hline Boundary & $\begin{array}{l}\text { where newcomers aim to sustain participation and membership } \\
\text { across the boundaries of different communities of practice. }\end{array}$ \\
\hline Peripheral & $\begin{array}{l}\text { where newcomers do not aim for full membership but where } \\
\text { limited 'access to a community and its practice ... [is] } \\
\text { significant enough to contribute to one's identity'. }\end{array}$ \\
\hline Outbound & $\begin{array}{l}\text { while being directed out of a community may involve } \\
\text { 'developing new relationships, finding a different position with } \\
\text { respect to a community, and seeing the world and oneself in } \\
\text { new ways' }\end{array}$ \\
\hline
\end{tabular}

(Wenger, 1998, pp. 154-155).

Non-participation may in some cases be enabling, such as when newcomers choose a peripheral trajectory and accept elements of non-participation as part of their identity. Participant preference for a peripheral or boundary trajectory reflects the power of 'individuals and communities to define and affect our relations to the rest of the world' (Wenger 1998, 167).

Over time, forms of participation and identities change as newcomers themselves become old-timers with respect to the next set of newcomers (Lave and Wenger 1991, 56). Underlying this process of reproduction of the community are tensions inherent in the competitive relationship between newcomers and the old-timers they will eventually replace. As newcomers move towards full participation, the community of practice itself changes, as do the power relations between newcomers and old-timers.

Newcomers are caught in a dilemma. On the one hand they need to engage in existing practice which has developed over time: to understand it, to participate in it, and to become full members of the community in which it exists. On the other hand they have a stake in its development as they begin to establish their identity in its future. (Lave and Wenger 1991, 115)

\section{Communities of practice in the Department of Design}

The study identified three communities of practice within the department (Figure 1). Teaching in the undergraduate programme was managed and monitored by an active programme committee that formed the hub of an undergraduate teaching community 
of practice (CoP). The regular programme committee meetings helped to consolidate shared understandings within the undergraduate teaching CoP. However it was only junior and middle level academics who participated in undergraduate teaching. Senior academics only taught at the postgraduate level and this resulted in a significant separation of sites of participation of junior and senior academics. Stuart, a former head of department (HOD), explained how this division of labour had evolved.

The [undergraduate] programme is much more structured ... That's much easier work to assess. The [postgraduate] programme is different and there you get much more senior people who've been teaching for years and I think are better able to assess that work. ... What has tended to happen . . . when I was HOD, was that the younger staff went to the [undergraduate] programme . . . and the more senior staff went to the [postgraduate] programme. (para. 110.)

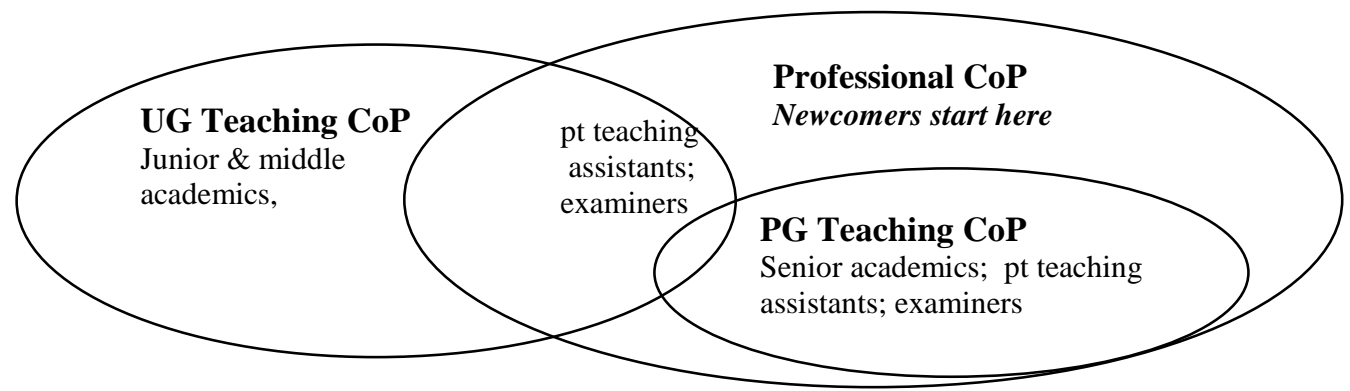

Figure 1. Communities of practice in the Department of Design

Traditionally graduates of the profession who aspired to becoming academics began their careers by first working in practice and establishing themselves as members of a broad professional CoP. During this time many chose to serve as external examiners, part-time lecturers or studio assistants in higher educational institutions. As such they accumulated substantial capital associated with the profession and some experience of teaching prior to embarking on a full-time career as academics.

Engagement with professional practice, to varying degrees, formed a central feature of the identity of an academic in the department and most academics participated in the professional CoP. While this professional CoP did not have the same coherence as the undergraduate teaching $\mathrm{CoP}$, its presence in the department was sustained by the professional involvement of key senior academic members of staff and the large numbers of professional practitioners who taught part time or examined within the educational programmes. Furthermore the main objective of the teaching programmes at both undergraduate and postgraduate level was to produce graduates who were able to work as professionals. Teaching and assessment practices were therefore strongly aligned with this objective.

As senior academics aligned themselves significantly with the professional CoP, the postgraduate teaching for which they were responsible was substantially embedded within this community of practice (Figure 1).

The particular configuration of communities of practice represented in Figure 1 is a significant feature of the academic field within which the department was situated. This configuration emphasises the separation of junior and senior academics and 
defines the possible identity trajectories that academics might take. This configuration differed substantially from that evident in the other two case studies (Jawitz, forthcoming). In the case study based in the Social Sciences (Jawitz 2007), the configuration consisted of two largely separate communities of practices, namely an undergraduate teaching $\mathrm{CoP}$ and a research $\mathrm{CoP}$ with a postgraduate $\mathrm{CoP}$ embedded within it. In the case study of a department in the Natural Sciences (Jawitz 2008 in press) the research CoP was dominant and had a teaching CoP embedded within it.

\section{Tensions between professional and academic identities}

Stuart, one of the senior academics, acknowledged the tension in the department between 'those who are full time working here all the time doing research and teaching, and those of us who are teaching and doing administration but also practising.' Perceptions of the origins and basis of this tension dominated the interviews. Several of the junior and middle level academics interviewed criticised the senior academics for spending too much time on their private professional work and not providing leadership in the department's affairs. One described the antagonism between 'people that practice and people that teach.' Another felt it was 'unacceptable' that many of the full time senior academics were 'just not present' and did not 'get involved in the culture of the [department].' As a result the management and administration of the educational programmes was left to 'the few people that's around in the afternoon'.

At stake appeared be the commitment that individual academics displayed to their participation in one or other of the teaching and professional communities of practice. Malcolm explained that this tension had not always existed in the department. In the mid-1970's, academics in the then new department had focussed their efforts on building the educational programme and there had been very limited involvement in professional practice.

We were committed to making a good [department]. We didn't do any research . . . very few of us did any practice at all ... We worked a full time job getting the [department] going ... [ [It] became the strongest . . . in the country and . . . as strong as the top three in the UK. (para. 42-45.)

However, by the mid 1980's, in an indication of shifting priorities and changing academic identities, several senior academics in the department began developing their professional practice or their research, and spending less time within the department.

[Ettiene] went off and did his practice. Trevor and Lillian got their research careers going . . . They did their work at home . . . Roger got a bit of [professional] work and he pulled out ... So . . . from this very coherent group all working together with this fantastic focus ... it sort of split out. (Malcolm, para. 51.)

At the time of this study the majority of the younger and middle level academics in the department displayed a strong sense of commitment to building up and improving the educational programmes. As a result several had decided to limit their involvement in professional practice. Frank had registered for a postgraduate degree in education. Another explained that her 'interest in practice' didn't compare to the 
'joy' she got from teaching. She described herself as a 'happy academic' who 'loves teaching.'

As someone who had spent several years in practice before embarking on an academic career, Frank acknowledged the value of this experience. He regarded the educational qualification as a professional degree that focussed on 'teaching students to be able to succeed in practice' and felt that 'students respected that sort of body of work.' Given the aim of the educational programme to prepare students to become professionals, the design tasks throughout the curriculum played an important role in inducting students into the profession. The judgement of student performance in design was strongly aligned with the process of project evaluation in professional practice.

The role of professional practitioners in the department was central in sustaining the authenticity of the assessment practice and the strong relationship between teaching and professional practice. Regular group discussions that formed part of the assessment practice, provided significant opportunities for legitimate, and at times peripheral, participation for professional practitioners serving as part-time lecturers and examiners. Those who eventually joined the department as full time academics, such as Frank, Pat, Majdi and Zaid, entered the department with strong professional identities. They brought with them the priorities and values of professional practice, strengthening the dominant role of professional capital in the field.

Frank highlighted the distinction between the identities of those prioritising a professional career and those choosing to develop a 'purely' academic career within the department. He contrasted the roles of a 'pure' academic, committed to the traditional roles of teaching and research, with that of the practitioner. He argued that senior academics in the department had strong professional practitioner identities and were unable to serve as role models for new academics in the development of their academic identities.

It's a department which is academically driven by . . . people who have a practitioners' identity rather than a purely academic one . . . and has been for a long time. . . . Teaching happens . . . from a practice base rather than from a theoretical base, and . . . there's a kind of lack of research culture historically. And it affects the induction of staff, because the role models are people who are practitioners and who succeed as practitioners rather than as academics. (para. 51.)

The difference between practitioner and academic identities reflected a difference in values between those committed to developing the profession and those committed to developing the discipline within the field of higher education. This was evident at times in the teams of markers that included academic internal examiners and the professional external examiners.

At exit level . . . the external examiner is there to sort of defend the needs of the organised profession to ensure that graduates are competent to enter the industry. ... An internal examiner, who's sort of defending the intellectual integrity of the piece of work, might have very little interest in those things. (Frank, para. 157.) 


\section{An emergent research identity}

The absence of a research $\mathrm{CoP}$ in the department was related to fact that the outputs of practice most valued in the professional CoP, namely physical products produced for commercial purposes, were not regarded as research outputs by the broader academic community. The limited number of research papers in Design usually focussed on relatively marginal theoretical or historical aspects of the discipline. As a result there was no sign of a research CoP within the department.

While the field associated with the discipline favoured the accumulation of professional capital, the field of higher education valued the development of research capital. Stuart described the pressure in Design programmes internationally to fall in line with 'traditional academic practice'. As a result 'two very distinct fields' had emerged: namely, a 'field of practice' and a 'field of theory of teaching'. He remarked that in the United States of America (USA) the situation had shifted to the point where design academics were 'utterly committed to an academic career with no engagement in practice and under pressure to produce new knowledge and research’.

The SAU promoted itself as a research-intensive university and offered substantial institutional recognition for research output. As a result Stuart explained that there was increasing pressure on members of his department to become more 'professional as academics' and to 'produce knowledge' that is recognized by the academic community. He argued that it was very difficult for people like himself to find a 'clear way [to] bring that practice work back into the [department] so that it both constitutes research and it constitutes teaching material'. However he pointed to the next 'generation of young people . . committed to a dedicated academic career' who would be better able to achieve this and referred to a growing trend amongst the younger academic staff to include formal research as part of their academic identities.

Clear examples of this were provided by Neville, who had recently completed his $\mathrm{PhD}$, and Hanlie who had embarked on a research career track while at her previous institution. The indication that other new academics Majdi and Zaid were considering doing a $\mathrm{PhD}$ further strengthened the possibility that a research CoP might evolve in future in the department. This development was likely to be supported by the high value placed on research within SAU and field of higher education. However it could further complicate the tensions surrounding the multiple academic identities within the department as it would require devoting more time to developing their research and less time building up their professional expertise, or teaching.

\section{Identity and career trajectories}

As evident above, academics in the department were clearly divided into those who saw themselves primarily committed to teaching, and in some cases research, and those who saw themselves primarily as professional practitioners. However the identity trajectories of individual academics depended on their career paths and their participation in the departmental communities of practice. The relationship between the primary communities of practice is reflected in Figure 1 and forms the framework 
for analysing the range of identity trajectories that were present in the department (Figure 2).

The dominance of the professional community of practice was reflected in the outbound identity trajectory from the undergraduate teaching CoP into the professional CoP of several senior academics, such as Stuart and Roger (Figure 2a). This trajectory can be regarded as the traditional paradigmatic trajectory that signified success and achievement as an academic in the discipline. Both Stuart and Roger were highly regarded in the profession and their designs had won several awards.

In contrast, as explained earlier, Frank had disengaged himself from professional practice and devoted his attention to teaching. Evidence of this was his participation in a postgraduate degree in education and his involvement in managing the undergraduate teaching programme. As such his identity trajectory was representative of an inbound trajectory from the professional CoP into the undergraduate CoP (Figure 2b).

Several academics in the department, including Pat, Zaid and Majdi, chose to sustain participation in both the professional and undergraduate teaching CoPs (Figure 2c). Given the tensions described above maintaining this boundary trajectory represented a significant challenge, and in the years that followed this study both Pat and Majdi resigned from the department and returned to professional practice with Majdi retaining some part-time involvement in teaching.

Hanlie and Neville are examples of individuals who had no experience of professional practice when they began their academic careers. They represent an alternative career trajectory into the discipline. Neville had first obtained his PhD in the USA before his appointment in the department. Hanlie had begun her academic career at another South African university where she had been involved in research before applying for a job at SAU. Their efforts to sustain and develop their research along with their teaching is depicted in Figure $2 \mathrm{~d}$ as representing boundary trajectories linking distant research communities of practice elsewhere with the undergraduate teaching $\mathrm{CoP}$ in the department. Their determination to sustain this boundary trajectory represents an emergent identity trajectory within the department. 


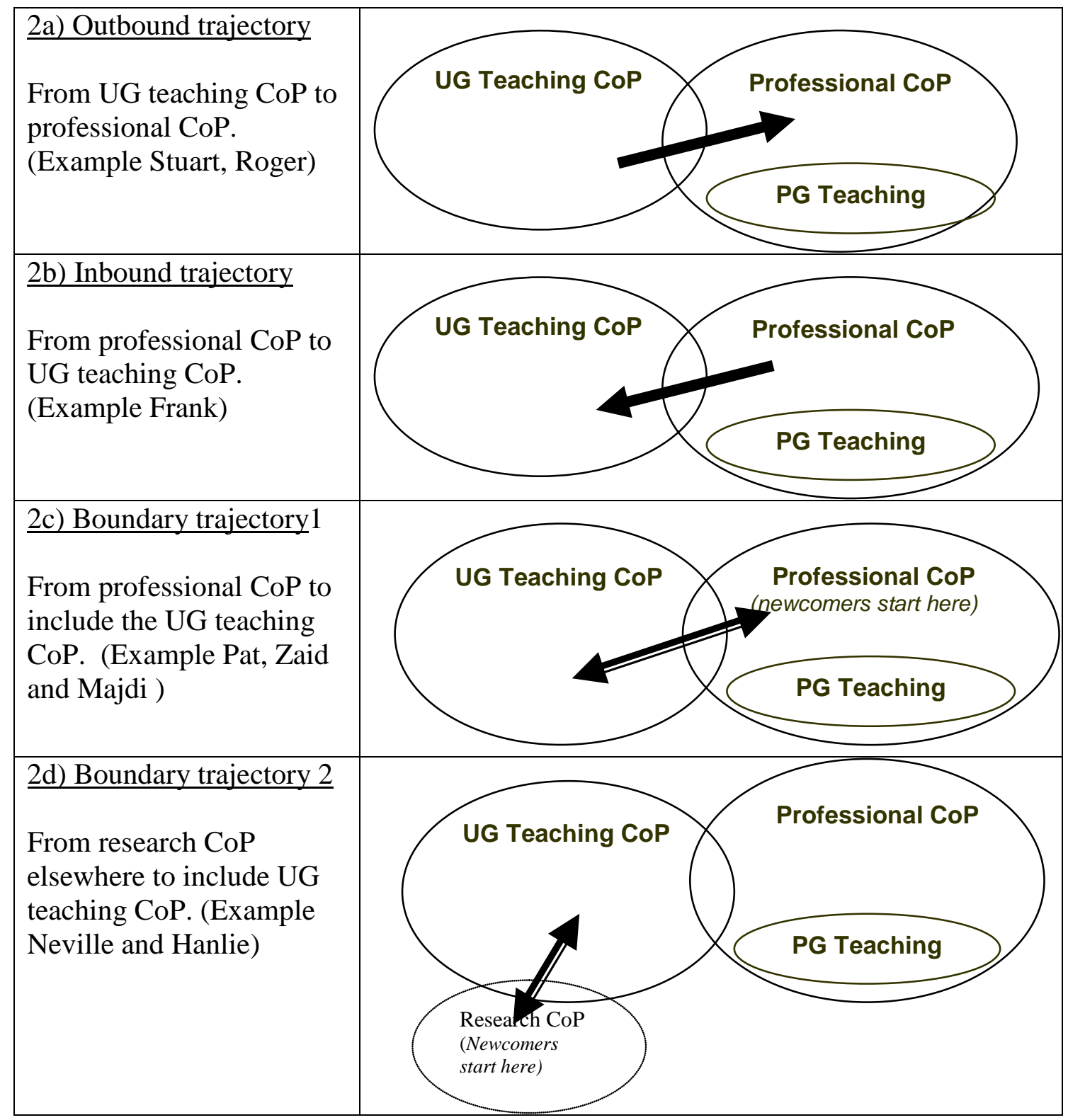

Figure 2. Identity trajectories in the Department of Design

\section{Conclusion}

The importance of the discipline is often stressed in understanding the various forms of academic practice in higher education. However this study shows that practice within a discipline is by no means homogenous and provides evidence of the tensions surrounding membership of competing communities of practice within a discipline.

The particular forms and paths of academic identity formation within the Department of Design at SAU were shaped by the dominant role of the professional CoP and the tensions arising out the competing commitments to the development of teaching, research and professional practice. While there was substantial distance between the professional world of practice and academic research, the link between professional work and teaching was exceptionally strong, reinforced by the presence of many parttime practitioners in the department, and the authentic forms of assessment and teaching modelled on practice. As a result it was the development of professional 
capital that was most valued within the discipline, as evidenced by senior academics spending a great deal of time sustaining their professional practice. However they were dependent on large numbers of part-time staff in the teaching programme to enable them to do so.

The case study revealed a complex relationship between issues of identity construction and participation in teaching, research and professional practice that define the academic field in the Department of Design. The notion of an academic identity was contested despite the dominance of the professional CoP. The younger academics challenged the way in which their more senior colleagues placed greater value in participation in the professional CoP. Their commitment to developing the educational programmes in the department and in some cases to undertake formal research was supported by the institutional notion of the academic identity involving teaching and research. The presence of multiple identity trajectories in the department reflects their individual agency in choosing an academic career path and creates the possibility of a changed notion of the academic within the discipline.

While the majority of full time academics in the department had followed the traditional career trajectory from professional practice into academia, the arrival of two academics with no experience of professional practice but significant research expertise represents the possible emergence of an alternative career trajectory into the discipline.

As academic development practitioners attempt to embed their own practices within the disciplinary contexts of the colleagues they work with, they would do well to reflect on the internal dynamics that might exist within the discipline that give rise to competing notions of academic identity and a range of identity trajectories.

\section{References}

Archer, Louise. 2008. The neoliberal subjects? Young/er academics' constructions of professional identity. Journal of Education Policy 23, no. 3: 265-85.

Austin, Ann E. 1990. Faculty Cultures, Faculty Values. New Directions for Institutional Research 68 (Winter).

Barnett, Ronald. 1999. Learning to work and working to learn. In Understanding Learning at Work, edited by David Boud and John Garrick, 29-44. Routledge.

Becher, Tony, and Paul Trowler. 2001. Academic Tribes and Territories (Second Edition). The Society for Research into Higher Education \& Open University Press.

Billett, Stephen. 2004. Learning through work: Workplace participatory practices. In Workplace learning in Context, edited by Helen Rainbird, Alison Fuller, and Anne Munro, 109-25. London: Routledge.

Clark, Burton R. 1987. The Academic Life: Small Worlds, Different Worlds. New Jersey: The Carnegie Foundation for the Advancement of Teaching.

Clegg, Sue. 2008. Academic identities under threat? British Educational Research Journal 34, no. 3: 329-45.

Fuller, Alison, Heather Hodkinson, Phil Hodkinson, and Lorna Unwin. 2005. Learning as peripheral participation in communities of practice: A reassessment of key concepts in workplace learning. British Educational Research Journal 31, no. 1, February: 49-68. 
Fuller, Alison, Anne Munro, and Helen Rainbird. 2004. Introduction and Overview. In Workplace Learning in Context, edited by Helen Rainbird, Alison Fuller, and Anne Munro, 1-18. London: Routledge.

Henkel, M. 2000. Academic Identities and Policy Change in Higher Education. London: Jessica Kingsley Publishers.

Hodkinson, Heather, and Phil Hodkinson. 2004. Rethinking the concept of community of practice in relation to schoolteachers' workplace learning. International Journal of Training and Development 8, no. 1: 21-31.

Jawitz, Jeff. 2007. New Academics negotiating communities of practice: Learning to swim with the big fish. Teaching in Higher Education 12, no. 2: 185-197.

Jawitz, Jeff. 2008. In press. Learning to assess in the academic workplace: case study in the Natural Sciences. South African Journal of Higher Education 22, no. 5

Jawitz, Jeff. Forthcoming. Learning in the academic workplace: the harmonization of the collective and the individual habitus. Studies in Higher Education

Jenkins, Alan. 2000. The Relationship between Teaching and Research: Where does geography stand and deliver? Journal of Geography in Higher Education 24, no. 3: 325-51.

Jenkins, Alan, Rosanna Breen, Roger Lindsay, and Angela Brew. 2003. Reshaping Teaching in Higher Education. London: Kogan Page.

Knight, Peter T., and Paul Trowler. 2000. Department-level cultures and the improvement of learning and teaching. Studies in Higher Education 25, no. 1: 69-83.

Kogan, Maurice. 2000. Higher Education Communities and Academic Identity. Higher Education Quarterly 54, no. 3: 207-216.

Lave, Jean, and Etienne Wenger. 1991. Situated Learning: Legitimate peripheral participation. Cambridge: Cambridge University Press.

Neumann, Ruth. 2001. Disciplinary Differences and University Teaching. Studies in Higher Education 26, no. 2: 135-46.

Shulman, Lee. 1993. Teaching as community property: Putting an end to pedagogic solitude. Change 25, no. 6: 6-7.

Trowler, Paul, and Peter T. Knight. 2000. Coming to Know in Higher Education: Theorising faculty entry to new work contexts. Higher Education Research and Development 19, no. 1: 27-42.

Wenger, Etienne. 1998. Communities of Practice Learning, Meaning, and Identity. Cambridge: Cambridge University Press. 